\title{
Huanglongbing modifies quality components and flavonoid content of
}

\section{'Valencia' oranges}

Roberto Massenti $^{\mathrm{a}}$, Riccardo Lo Bianco ${ }^{\mathrm{a}^{*}}$, Amandeep K. Sandhu $^{\mathrm{b}}$, Liwei Gu ${ }^{\mathrm{b}}$, Charles Sims ${ }^{\mathrm{b}}$

${ }^{\mathrm{a} D e p a r t m e n t ~ o f ~ A g r i c u l t u r a l ~ a n d ~ F o r e s t ~ S c i e n c e s, ~ U n i v e r s i t y ~ o f ~ P a l e r m o, ~ P a l e r m o, ~ I t a l y . ~}$

${ }^{\mathrm{b}}$ Department of Food Science and Human Nutrition, University of Florida, Gainesville, Florida, USA.

Correspondence to: Riccardo Lo Bianco, Department of Agricultural and Forest Sciences, University of Palermo, Viale delle Scienze, 90128 Palermo, Italy. E-mail:

riccardo.lobianco@unipa.it

This article has been accepted for publication and undergone full peer review but has not been through the copyediting, typesetting, pagination and proofreading process, which may lead to differences between this version and the Version of Record. Please cite this article as doi: 10.1002/jsfa.7061

This article is protected by copyright. All rights reserved 


\begin{abstract}
BACKGROUND: In order to evaluate the effect of HLB on quality components and flavonoid contents of 'Valencia' oranges, fruit from non-infected trees (control), from infected trees but symptom-less (asymptomatic) and from infected trees and showing clear HLB symptoms (symptomatic) were harvested in March and in May, 2013. Fruit peel, pulp and juice were separated, main quality components were determined, and hesperidin, nobiletin, tangeretin, narirutin and didymin were quantified using liquid chromatography. RESULTS: Peel color, TSS and citric acid were similar in control and asymptomatic fruits. Symptomatic fruits were smaller, yielded less juice, had higher acidity and lower sugar and peel color than control fruits. In the peel, hesperidin, nobiletin, tangeretin, narirutin and didymin were higher in symptomatic than in asymptomatic and control fruits. Peel flavonoids decreased with fruit maturation. Also in pulp and juice, flavonoid content was higher in symptomatic than in asymptomatic and control fruits.

CONCLUSIONS: These results show that asymptomatic fruits are similar to control fruits more than to symptomatic fruits, suggesting that secondary metabolism and physical properties of fruits are only affected at a later and more advanced stage of HLB infection. Despite the significant loss of quality, fruit with clear HLB symptoms accumulate high quantities of flavonoids in peel and pulp.
\end{abstract}

Keywords: Citrus greening, fruit pulp, hesperidin, juice yield, narirutin, peel color

\title{
INTRODUCTION
}

Citrus Greening disease, or Huanglongbing (HLB), is one of the most harmful diseases for citrus. All commercial citrus species and cultivars are susceptible, regardless of rootstocks, and HLB represents a serious threat for regions still free of the disease, such as the 
Mediterranean basin, Western Asia, Australia and Pacific Ocean islands. The causal agent of HLB is the endogenous bacterium Candidatus Liberibacter spp., vectored and injected into the phloem by two psyllid species, Diaphorina citri in Asia and in America and Trioza erytreae in Africa ${ }^{1,2}$. When vectored into a citrus tree, the bacterium triggers a cascade of events causing phloem dysfunction, cellular collapse, and over accumulation of carbohydrates in leaves ${ }^{3}$.

A tree in early stages of infections can be identified among many symptomless neighboring trees by the presence of one or several yellow shoots, which is a typical symptom unique to HLB. In leaves, another typical symptom of HLB is the so called 'blotchy mottle'. In addition to these symptoms, the leaves may become thicker and leathery.

HLB also induces very characteristic symptoms to fruits which remain small, asymmetric, misshapen and poorly colored. Also, in a cross-sectioned fruit, it is easy to see the small, brownish-black aborted seeds, highly typical of $\mathrm{HLB}^{3}$. After transmission of the bacterium, infected Citrus trees respond with a wide array of physiological and chemical reactions resulting in a sequence of symptoms, from mild chlorosis to distinct mottling associated with an increase in bacterial concentrations ${ }^{4}$. Starch, sucrose and fructose, whose concentration is directly proportional to that of secondary metabolites, increase significantly in infected sweet orange leaves ${ }^{5}$, although those are not symptoms unique to HLB $^{6}$.

According to McClean and Oberholzer ${ }^{7}$ and McClean and Schwarz ${ }^{8}$, juice of HLB symptomatic fruit has less quality and tastes bitter. Juice from symptomatic fruit has also higher acidity, lower sugars and lower brix/acid ratio, resembling juice from less mature fruits ${ }^{9}$. HLB infected fruits show greater contents of terpenes, hesperidin, naringenin, quercetin, limonin and nomilin aglycones compared to healthy fruits ${ }^{9}$.

Flavonoids are secondary metabolites synthesized from glucose via the shikimic acid pathway $^{10}$. In plants, they have primarily a defensive function, acting as antioxidants ${ }^{11}$. In 
humans, they exert several beneficial properties such as antitumor and anti-inflammatory activity and cardiovascular protection. Moreover, they can protect against high blood pressure and cholesterol ${ }^{12}$. The flavanone hesperidin is the predominant flavonoid in most citrus fruits but its content depends upon the cultivar, environmental growing conditions and maturity stage $^{13-15}$

The aim of this study was to determine the effect of HLB disease on flavonoid content in peel, pulp and juice of 'Valencia' oranges. Studying these responses could improve our understanding of plant defense mechanisms against HLB infection as well as suggest alternative uses for unmarketable, infected oranges, and above all their fruit peel, where flavonoids are mostly concentrated.

\section{EXPERIMENTAL}

'Valencia' orange fruits used in this study were obtained from groves at the Citrus Research and Education Center, Lake Alfred, FL, USA. Fruits were harvested on 29 March and 27 May, 2013, and divided into three groups: oranges showing clear HLB symptoms (small, lopsided, aborted seeds) and collected from HLB-infected trees (symptomatic); oranges with no HLB symptom but collected from HLB-infected trees (asymptomatic); and oranges with no visual symptom and collected from healthy trees (control). Infected trees were those that tested positive for the HLB bacterium by PCR analysis. Asymptomatic fruits were collected from infected trees, but from those limbs that did not show any visual symptom like shoot yellowing or leaf blotchy-mottle. This latter condition is generally indicative of an initial stage of HLB disease.

\section{Determination of fruit quality components}

At each date, 20 to $30 \mathrm{~kg}$ of fruits of each group as described above were harvested and transfered to the laboratory in large bags. A sub-sample of 20 fruits for each group was 
randomly taken and divided into five sets each of four fruits. Each set of fruit was weighed, washed, photographed with a digital camera under controlled light conditions, and squeezed with an electric reamer juicer. In order to determine intensity of fruit peel color, digital images were analyzed using an algorithm that converts images from RGB to CIE 1976 L*a*b format, extracts the fruit from the image (removing the image background) and quantifies color characteristics as the weighted distance of each pixel in the image from a reference sample (best colored area interactively chosen from a well-colored fruit). The output is an index ranging from 0 (no orange) to 1 (full orange).

Juice of each set of fruits was weighed to determine juice yield as a percentage of total fruit weight. Total soluble solids (TSS) were measured in the juice of each set using an optical refractometer. Juice $\mathrm{pH}$ and titratable acidity were determined using a $\mathrm{pH}$ meter and titration to $\mathrm{pH} 8.2$ with $0.1 \mathrm{~N} \mathrm{NaOH}$. Total juice acidity was expressed in in grams of citric acid per 100 milliliters of juice. Juice samples were refrigerated at $4{ }^{\circ} \mathrm{C}$ for subsequent analysis.

\section{Flavonoid extraction}

Pulp was removed by hand from each squeezed fruit, weighed and stored at $-29^{\circ} \mathrm{C}$. Similarly, peel of each set of fruits was cut in small pieces, weighed and stored at $-29{ }^{\circ} \mathrm{C}$. Pulp and peel were freeze-dried at $-50{ }^{\circ} \mathrm{C}$, weighed again and ground into powder. Pulp and peel powders were stored at $-29^{\circ} \mathrm{C}$. Subsequently, $1 \mathrm{~g}$ of peel or pulp powder for each set of fruits was mixed with $20 \mathrm{ml}$ of pure methanol and the suspension was sonicated for $60 \mathrm{~min}$ in an ultrasonic bath at room temperature. The sonicated suspension was filtered and methanol extracts were stored at $-29^{\circ} \mathrm{C}$.

A solution containing $5 \mathrm{ml}$ of unfiltered orange juice and $20 \mathrm{ml}$ of $70 \%$ methanol (v:v) was centrifuged at $4000 \mathrm{rpm}$ for 15 minutes at $20{ }^{\circ} \mathrm{C}$. The supernatant was filtered and stored at $-29{ }^{\circ} \mathrm{C}$. The same procedure was repeated with fruit harvested at the end of May, for a total 
of 90 methanolic extracts.

\section{Flavonoid quantification}

Hesperidin, nobiletin, tangeretin, narirutin and didymin were quantified using an Agilent Technologies 1200 Series HPLC system (Agilent Technologies, Santa Clara, CA, USA) equipped with a 1024-element photodiode array detector and an Agilent Zorbax SB-C 18 column $(250 \mathrm{~mm} \times 4.6 \mathrm{~mm}$ i.d., $5 \mu \mathrm{m}$ particle size $)$ at room temperature. A gradient elution of acetonitrile (solvent A) and millipore water (solvent B) at a flow rate of $1 \mathrm{ml} \mathrm{min}{ }^{-1}$ was used according to the program reported in Tab. 1. Re-equilibration time between two individual runs was $2 \mathrm{~min}$.

Hesperidin, nobiletin and tangeretin standards (HPLC grade) were purchased from Thermo Fisher Scientific (Waltham, MA, USA), narirutin and didymin standards from Indofine Chemical Company (Hillsborough, NJ, USA). Standards were diluted to obtain 5 different solutions: $6 \mathrm{mg}$ of hesperedin in $1 \mathrm{ml}$ of dimethyl sulfoxide; $3.8 \mathrm{mg}$ of narirutin, 1 $\mathrm{mg}$ of tangeretin, $1 \mathrm{mg}$ of nobiletin and $1 \mathrm{mg}$ of didymin each in $1 \mathrm{ml}$ of methanol. A mixed standard stock solution was prepared by mixing $1 \mathrm{ml}$ of each previous solution with $1 \mathrm{ml}$ of pure methanol. Standard curves were constructed by sequential dilution at six different concentrations of working standard solutions. Data were analyzed using Chemstation software (Version B. 01.03, Agilent Technologies, Palo Alto, CA). Retention times were investigated and sample chromatograms were compared with standard chromatograms to get flavonoid concentrations contained in orange peel, pulp and juice.

\section{Statistical analysis}

Data were compared by analysis of variance with fruit type (control, asymptomatic, and symptomatic) and harvest period as main factors, and fruit type $\mathrm{x}$ harvest period as the sole interaction. Associations between peel color and juice acidity or soluble solids were tested by linear regression; differences between slopes were assessed by t-test. Statistical tests were 
performed using SYSTAT procedures (Systat Software Inc., Richmond, Ca., USA). Averages and statistics pooled by main factor were summarized in tables when interactions were nonsignificant.

\section{RESULTS AND DISCUSSION}

Fruits showing HLB symptoms were $37 \%$ smaller and yielded $6 \%$ less juice than control fruits (Tab. 1). Also, fruits harvested in May were 10\% bigger, but yielded $7 \%$ less juice than fruits harvested in March. Peel color and TSS were higher in control and asymptomatic than in symptomatic fruits, whereas acidity was higher in symptomatic than in control and asymptomatic fruits (Tab. 2). The TSS/AC ratio was highest in control fruits, followed by asymptomatic and lowest in symptomatic fruits as previously found by Dagulo et al. ${ }^{9}$. Also, peel color, juice TSS and acidity increased with maturation (Tab. 2). There was no significant change in TSS/AC over the considered period. The lack of an expected increase in TSS/AC from March to May is mostly due to symptomatic fruits; a significant TSS/AC increase, indicating a real advancement of fruit maturation, is observed in control fruits (data not shown).

Total acidity was linearly related to peel color but with different slopes depending on fruit type (Fig. 1); one steeper for symptomatic fruits and the other less steep for asymptomatic and control fruits $(\mathrm{P}=0.015)$. Higher acidity in symptomatic fruits may be the result of a metabolic adjustment in the attempt to lower $\mathrm{pH}$ and increase sink strength (attract more sugars), as suggested by Hockema and Etxeberria ${ }^{16}$.

There was also a direct linear relationship between peel color and soluble solids common to all fruit types (Fig. 2), suggesting that sweeter fruit are also better colored as previously observed in satsuma ${ }^{17}$. As expected, values of symptomatic fruit were at the low left end of the lines, showing an evident sugar deprivation caused by HLB and a substantial 
loss of fruit quality.

Flavonoids were most abundant in peel, while juice exhibited only traces of hesperidin, narirutin and didymin; hesperidin was the most abundant flavonoid in all tissues and fruit types (Tabs. 3, 4, 5 and 6). The levels of flavonoids detected in our fruit were generally comparable to those reported in orange by Nogata et al. ${ }^{18}$ and Wang et al. ${ }^{19}$, but higher than those reported by Abeysinghe et al. ${ }^{20}$

In the fruit peel, narirutin and dydimin contents were higher in symptomatic fruits than asymptomatic and control fruits (Tab. 3). Hesperidin and nobiletin contents were highest in symptomatic fruits and lowest in control ones; asymptomatic fruits had an intermediate content. No interaction between fruit type and harvest was detected. Tangeretin levels exhibited a different behavior depending on harvest time. In March, tangeretin content of symptomatic and asymptomatic fruits was higher than that of control fruits (Tab. 4). In May, tangeretin content was highest in symptomatic fruits and lowest in control fruits, with asymptomatic fruits at an intermediate level. The level of all five compounds decreased with fruit maturation (Tabs. 3 and 4).

In the pulp, narirutin, hesperidin and dydimin contents tended to decrease with fruit maturation, especially in symptomatic fruits (Tab. 5). In March, narirutin, hesperidin and dydimin contents were higher in symptomatic fruits than in control and asymptomatic fruits. In May, only hesperidin exhibited significant differences, with highest levels in symptomatic fruits and lowest levels in control fruits (Tab. 5). Similar decreases of flavonoid contents in peel and pulp were reported in satsuma mandarin ${ }^{21}$.

In the juice, narirutin content tended to be highest in symptomatic fruits at both harvest times (Tab. 6). Hesperidin content was highest in symptomatic fruits and lowest in control fruits, only in May. Dydimin content was higher in symptomatic fruits than in asymptomatic fruits, only in May. Also, there is a general increase in hesperidin, narirutin and 
dydimin with fruit maturation (Tab. 6). This is in contrast with observations on satsuma mandarin ${ }^{21}$ and chinotto ${ }^{15}$ and opposite compared to trends observed in peel and pulp, suggesting that during 'Valencia' fruit maturation flavonoids may be partly moved from peel and pulp into the juice.

Chemical and physical properties of symptomatic fruits were significantly modified, resembling assimilate deprivation and a substantial delay in fruit maturation. Both of these events may be explained by phloem clogging and reduced assimilate translocation due to HLB infection ${ }^{3}$. Externally supplied simple sugars may in fact favor an increase of the primary metabolism ${ }^{22}$. The increase in the primary metabolism can, in turn, lead to an increase in the capacity of the fruit to attract and accumulate (sink) sugars produced in the leaves (source) during photosynthesis, as well as an increase in the synthesis of organic acids and their conversion into sugars during maturation ${ }^{23}$. Ultimately, this may explain the smaller final fruit size, but also the decrease of sensory quality and nutritional levels in symptomatic fruits since the end-products of primary metabolism (aminoacids, sugars, organic acids) are in turn substrates for synthesis of secondary metabolites.

Chemical and physical properties of asymptomatic fruits, which are supposed to be from trees at an initial/intermediate level of infection, were similar to those of control fruits more than to those of symptomatic ones. This suggests that secondary metabolism and physical properties of fruits are only affected at a later and more advanced stage of HLB infection.

When flavonoid contents in the three tissues were averaged and expressed as $\mathrm{mg} \mathrm{g}^{-1}$ of fruit considering the incidence of each tissue on the whole fruit (weighed average), differences between harvest dates and among fruit types tended to level off, especially in more mature fruits (Tab. 7). Also, asymptomatic fruits harvested in March were generally richer in flavonoids than control and symptomatic fruits. These trends on a whole fruit basis 
show that HLB infection influences primarily the partitioning of flavonoids into specific tissues rather than the total content in the fruit. Maintaining total flavonoid contents in symptomatic fruits must be accomplished at the primary expense of primary metabolites, as shown by reduced soluble solids and color development.

\section{CONCLUSIONS}

Overall, HLB interferes with starch and sugar metabolism in leaves and fruits. Also, HLB stops the transport of nutrients in the phloem, reducing photosynthesis ${ }^{5}$. All this determines the chaos in the networks of plant hormones, such as ethylene, causing sugar accumulation in leaves and deprivation in fruits where they are preferentially diverted into flavonoids. In particular, HLB appears to arrest or slow down fruit growth and maturation as evidenced by low sugars and elevated acid levels in the juice, causing serious quality losses and posing serious problems on the marketability of symptomatic fruits to juice processors. On the other hand, flavonoid contents, and especially that of narirutin and hesperidin, is greatly increased in the peel and pulp of symptomatic fruits, offering interesting opportunities for the extraction of natural antioxidants from those plant tissues.

\section{REFERENCES}

1. Jagoueix S, Bovè JM and Garnier M, The Phloem-limited bacterium of greening disease of the protobacteria is a member of the alpha subdivision of the Proteobacteria. Intl J Syst Bacteriol 44:379-386 (1994).

2. Jagoueix S, Bovè JM and Garnier M, PCR detection of the two «Candidatus» liberibacter species associated with greening disease of citrus. Mol Cell Probe 10:43-50 (1996).

3. Bovè JM, Huanglongbing: A destructive, newly-emerging, century-old disease in citrus. J Tree Pathol 88:7-37 (2006). 
4. Coletta-Filho HD, Carlos EF, Alves KCS, Pereira MAR, Boscariol-Camargo RL, de Souza AA and Machado MA, In planta multiplication and graft transmission of 'Candidatus Liberibacter asiaticus' revealed by real-time PCR. Eur J Plant Pathol 126:53-60 (2010).

5. Fan J, Chen C, Brlansky RH, Gmitter Jr FG and Li Z-G, Changes in carbohydrate metabolism in Citrus sinensis infected with 'Candidatus Liberibacter asiaticus'. Plant Pathol 59:1037-1043 (2010).

6. Cimò G, Lo Bianco R, Gonzalez P, Bandaranayake W, Exteberria E and Syvertsen JP, Carbohydrate and nutritional responses to sterm girdling and drought stress with respect to understanding symptoms of huanglongbing in Citrus. Hort Sci 48:920-928 (2013).

7. McClean APD and Oberholzer PCJ, Greening disease of the sweet orange: evidence that it is caused by transmisable virus. S Afr J Agr Sci 8:253-276 (1965).

8. McClean APD and Schwarz RE, Greening or blotchy-mottle disease of citrus. Phytophylactica 2:177-194 (1970).

9. Dagulo L, Danyluk MD, Spann TM, Valim MF, Goodrich-Schneider R, Sims C and Rouseff R, Chemical characterization of orange juice from trees infected with citrus greening (Huanglongbing). J Food Sci 75:199-207 (2010).

10. Ververidis F, Trantas E, Douglas C, Vollmer G, Kretzschmar G and Panopoulos N, Biotechnology of flavonoids and other phenylpropanoid-derived natural products. Part II: Reconstruction of multienzyme pathways in plants and microbes. Biotech J 2:1235-1249 (2007).

11. Hernandez I, Alegre L, Van Breusegem F and Munné-Bosch S, How relevant are flavonoids as antioxidants in plants? Trend Plant Sci 14:125-132 (2009).

12. Mennen L, Sapinho D, de Bree A, Arnault N, Bertrais S, Galan P and Hercberg S, Consumption of foods rich in flavonoids is related to a decreased cardiovascular risk in apparently healthy franch women. J Nutr 134:923-926 (2004).

This article is protected by copyright. All rights reserved 
13. Mouly PP, Gaydou EM, Faure R and Estienne JM, Blood orange juice authentication using cinnamic acid derivates. Variety differentiations associated with flavanone glycoside content. J Agric Food Chem 45:373-377 (1997).

14. Rapisarda P, Carollo G, Fallico B, Tomaselli F and Maccarone E, Hydroxycinnamic acids as markers of Italian blood orange juices. J Agric Food Chem 465:464-470 (1998).

15. Barreca D, Bellocco E, Caristi C, Leuzzi U and Gattuso G, Flavonoid composition and antioxidant activity of juices from chinotto (Citrus $\times$ myrtifolia Raf.) fruits at different ripening stages. J Agric Food Chem 58:3031-3036 (2010).

16. Hockema BR and Etxeberria E, Metabolic contributors to drought-enhanced accumulation of sugars and acids in oranges. J Am Soc Hort Sci 126:599-605 (2001).

17. Iglesias DJ, Tadeo FR, Legaz F, Primo Millo E and Talon M, In vivo sucrose stimulation of colour change in citrus fruit epicarps: interactions between nutritional and hormonal signals. Physiol Plant 112:244-250 (2001).

18. Nogata Y, Sakamoto K, Shiratsuchi H, Ishii T, Yano M and Ohta H, Flavonoid composition of fruit tissues of citrus species. Biosci Biotechnol Biochem 70:178-192 (2006).

19. Wang YC, Chuang YC and Hsu HW, The flavonoid, carotenoid and pectin content in peels of citrus cultivated in Taiwan. Food Chem 106:277-284 (2008).

20. Abeysinghe DC, Li X, Sun C, Zhang W, Zhou C and Chen K, Bioactive compounds and antioxidant capacities in different edible tissues of citrus fruit of four species. Food Chem 104:1338-1344 (2007).

21. Moriguchi T, Kita M, Tomono Y, Endo Inagaki T and Omura M, Gene expression in flavonoid biosynthesis: Correlation with flavonoid accumulation in developing citrus fruit. Physiol Plant 111:66-74 (2001).

22. Roitsch T and Gonzalez MC, Function and regulation of plant invertases: sweet

This article is protected by copyright. All rights reserved 
sensations. Trends Plant Sci 9:606-613 (2004).

23. Roitsch T, Source-sink regulation by sugars and stress. Curr Opin Plant Biol 2:198-206 (1999).

This article is protected by copyright. All rights reserved 
Table 1. Gradient program showing the percentage of acetonitrile (solvent A) and millipore water (solvent B) used to elute samples during HPLC analysis.

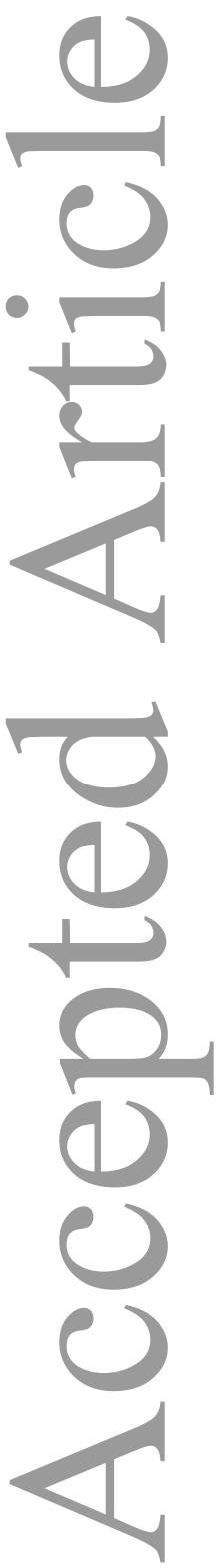

\begin{tabular}{ccc}
\hline Time (min) & Solvent A (\%) & Solvent B (\%) \\
\hline 0.00 & 22.00 & 78.00 \\
10.00 & 22.00 & 78.00 \\
35.00 & 61.00 & 39.00 \\
40.00 & 100.00 & 0.00 \\
45.00 & 22.00 & 78.00 \\
\hline
\end{tabular}

This article is protected by copyright. All rights reserved 
Table 2. Fruit quality of control, asymptomatic and symptomatic (showing HLB symptoms)

'Valencia' oranges harvested at the end of March and end of May. P-values refer to main factors from analysis of variance. Different letters indicate significant differences among levels of the HLB factor and for each compound (Tukey's test, $\mathrm{P} \leq 0.05$ ). TSS $=$ total soluble solids; $\mathrm{AC}=$ total juice acidity expressed in citric acid equivalents.

\begin{tabular}{ccccccc}
\hline Treatment & $\begin{array}{c}\text { Weight } \\
(\mathrm{g})\end{array}$ & $\begin{array}{c}\text { Juice yield } \\
(\%)\end{array}$ & Peel Color & $\begin{array}{c}\text { TSS } \\
\left({ }^{\circ} \mathrm{Brix}\right)\end{array}$ & $\begin{array}{c}\text { AC } \\
\left(\mathrm{g} 100 \mathrm{ml}^{-1}\right)\end{array}$ & TSS/AC \\
\hline Control & $183 \mathrm{~b}$ & $58.9 \mathrm{a}$ & $0.785 \mathrm{a}$ & $12.4 \mathrm{a}$ & $0.719 \mathrm{~b}$ & $11.0 \mathrm{a}$ \\
Asymptomatic & $208 \mathrm{a}$ & $57.8 \mathrm{ab}$ & $0.785 \mathrm{a}$ & $12.2 \mathrm{a}$ & $0.748 \mathrm{~b}$ & $10.4 \mathrm{~b}$ \\
Symptomatic & $115 \mathrm{c}$ & $55.5 \mathrm{~b}$ & $0.677 \mathrm{~b}$ & $8.51 \mathrm{~b}$ & $1.221 \mathrm{a}$ & $4.5 \mathrm{c}$ \\
\hline$P$ & $<0.001$ & 0.005 & $<0.001$ & $<0.001$ & $<0.001$ & $<0.001$ \\
\hline March & 160 & 59.5 & 0.729 & 9.35 & 0.752 & 8.58 \\
May & 178 & 55.2 & 0.769 & 12.7 & 1.043 & 8.71 \\
\hline$P$ & 0.007 & $<0.001$ & $<0.001$ & $<0.001$ & $<0.001$ & 0.407 \\
\hline
\end{tabular}

This article is protected by copyright. All rights reserved 
Table 3. Narirutin, hesperidin, didymin and nobiletin content $\left(\mathrm{mg} \mathrm{g}^{-1}\right)$ in the peel of control, asymptomatic and symptomatic (showing HLB symptoms) 'Valencia' oranges harvested at the end of March and end of May. P-values refer to main factors from analysis of variance.

Different letters indicate significant differences among levels of the HLB factor and for each compound (Tukey's test, $\mathrm{P} \leq 0.05$ ).

\begin{tabular}{ccccc}
\hline Factor level & Narirutin & Hesperedin & Didymin & Nobiletin \\
\hline Healthy & $2.53 \mathrm{~b}$ & $25.9 \mathrm{~b}$ & $1.66 \mathrm{~b}$ & $0.799 \mathrm{c}$ \\
Asymptomatic & $3.38 \mathrm{~b}$ & $27.8 \mathrm{ab}$ & $1.89 \mathrm{~b}$ & $1.036 \mathrm{~b}$ \\
Symptomatic & $4.85 \mathrm{a}$ & $33.6 \mathrm{a}$ & $2.42 \mathrm{a}$ & $1.267 \mathrm{a}$ \\
\hline$P$ & $<0.001$ & 0.009 & $<0.001$ & $<0.001$ \\
\hline March & 4.47 & 31.3 & 2.28 & 1.20 \\
May & 2.69 & 26.9 & 1.70 & 0.863 \\
\hline$P$ & $<0.001$ & 0.009 & $<0.001$ & $<0.001$ \\
\hline
\end{tabular}

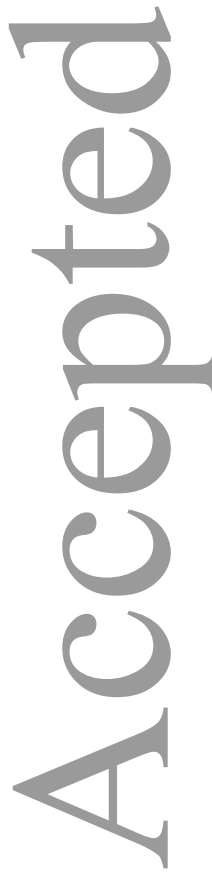

This article is protected by copyright. All rights reserved 
Table 4. Tangeretin content $\left(\mathrm{mg} \mathrm{g}^{-1}\right)$ in the peel of control, asymptomatic and symptomatic (showing HLB symptoms) 'Valencia' oranges harvested at the end of March and end of May. P-value refers to interaction between harvest period and fruit type from analysis of variance. Different letters indicate significant differences among types of fruit within each harvest (Tukey's test, $\mathrm{P} \leq 0.05$ ).

\begin{tabular}{ccc}
\cline { 2 - 3 } Marvest & Fruit type & Tangeretin \\
& Healthy & $0.118 \mathrm{~b}$ \\
& Asymptomatic & $0.173 \mathrm{a}$ \\
& Symptomatic & $0.204 \mathrm{a}$ \\
\hline \multirow{3}{*}{ May } & Healthy & $0.099 \mathrm{~b}$ \\
& Asymptomatic & $0.106 \mathrm{ab}$ \\
& Symptomatic & $0.141 \mathrm{a}$ \\
\hline
\end{tabular}

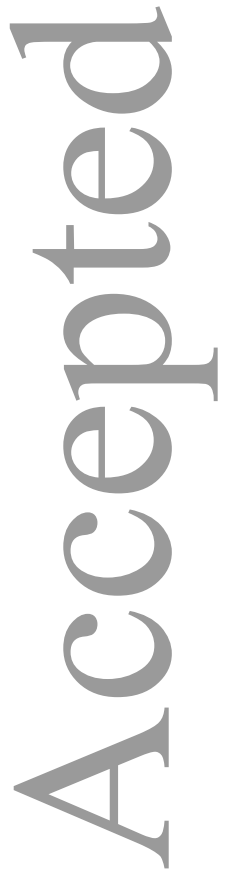


Table 5. Narirutin, hesperidin and didymin content $\left(\mathrm{mg} \mathrm{g}^{-1}\right)$ in the pulp of control, asymptomatic and symptomatic (showing HLB symptoms) 'Valencia' oranges harvested at the end of March and end of May. P-values refer to interaction between harvest period and fruit type from analysis of variance. Different letters indicate significant differences among types of fruit within each harvest (Tukey's test, $\mathrm{P} \leq 0.05$ ).

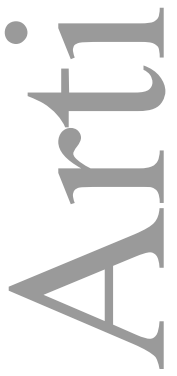

\begin{tabular}{ccccc}
\hline Harvest & Fruit type & Narirutin & Hesperedin & Didymin \\
\hline \multirow{3}{*}{ March } & Healthy & $3.42 \mathrm{~b}$ & $14.5 \mathrm{~b}$ & $1.62 \mathrm{~b}$ \\
& Asymptomatic & $3.86 \mathrm{~b}$ & $14.2 \mathrm{~b}$ & $1.71 \mathrm{~b}$ \\
& Symptomatic & $8.48 \mathrm{a}$ & $26.9 \mathrm{a}$ & $3.12 \mathrm{a}$ \\
\hline \multirow{3}{*}{ May } & Healthy & $3.43 \mathrm{a}$ & $9.89 \mathrm{c}$ & $1.69 \mathrm{a}$ \\
& Asymptomatic & $2.83 \mathrm{a}$ & $14.2 \mathrm{~b}$ & $1.46 \mathrm{a}$ \\
& Symptomatic & $4.01 \mathrm{a}$ & $19.2 \mathrm{a}$ & $2.03 \mathrm{a}$ \\
\hline & $P$ & $<0.001$ & $<0.001$ & $<0.001$ \\
\hline
\end{tabular}

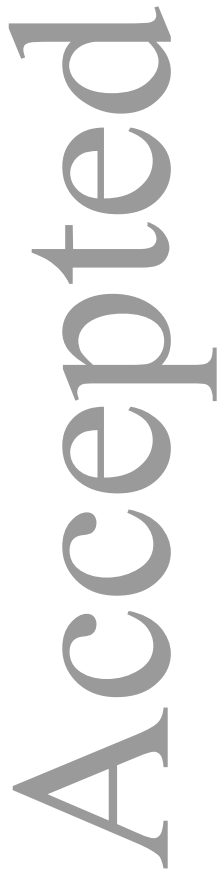

This article is protected by copyright. All rights reserved 
Table 6. Narirutin, hesperidin and didymin content $\left(\mathrm{mg} \mathrm{g}^{-1}\right)$ in the juice of control, asymptomatic and symptomatic (showing HLB symptoms) 'Valencia' oranges harvested at the end of March and end of May. P-values refer to interaction between harvest period and fruit type from analysis of variance. Different letters indicate significant differences among types of fruit within each harvest (Tukey's test, $\mathrm{P} \leq 0.05$ ).

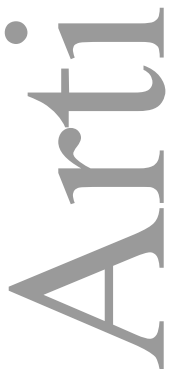

\begin{tabular}{ccccc}
\hline Harvest & Fruit type & Narirutin & Hesperedin & Didymin \\
\hline \multirow{3}{*}{ March } & Healthy & $0.033 \mathrm{~b}$ & $0.135 \mathrm{a}$ & $0.012 \mathrm{a}$ \\
& Asymptomatic & $0.042 \mathrm{ab}$ & $0.128 \mathrm{a}$ & $0.014 \mathrm{a}$ \\
& Symptomatic & $0.051 \mathrm{a}$ & $0.125 \mathrm{a}$ & $0.014 \mathrm{a}$ \\
\hline \multirow{3}{*}{ May } & Healthy & $0.053 \mathrm{a}$ & $0.157 \mathrm{a}$ & $0.019 \mathrm{ab}$ \\
& Asymptomatic & $0.049 \mathrm{a}$ & $0.182 \mathrm{ab}$ & $0.015 \mathrm{~b}$ \\
& Symptomatic & $0.060 \mathrm{a}$ & $0.192 \mathrm{a}$ & $0.020 \mathrm{a}$ \\
\hline & $P$ & 0.016 & 0.005 & 0.009 \\
\hline
\end{tabular}

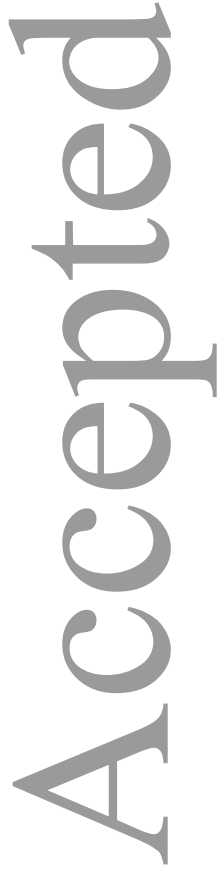

This article is protected by copyright. All rights reserved 
Table 7. Flavonoid content ( $\mathrm{mg} \mathrm{g}^{-1}$ of fruit, weighed average of peel, pulp and juice) in control, asymptomatic and symptomatic (showing HLB symptoms) 'Valencia' oranges harvested at the end of March and end of May. P-values refer to interaction between harvest period and fruit type from analysis of variance. Different letters indicate significant differences among types of fruit within each harvest (Tukey's test, $\mathrm{P} \leq 0.05$ ).

\begin{tabular}{cccccccc}
\hline Harvest & Fruit type & Narirutin & Hesperedin & Didymin & Tangeretin & Nobiletin \\
\cline { 2 - 7 } & Healthy & $0.716 \mathrm{~b}$ & $5.52 \mathrm{a}$ & $0.401 \mathrm{~b}$ & $0.017 \mathrm{~b}$ & $0.123 \mathrm{~b}$ \\
& March & Asymptomatic & $1.180 \mathrm{a}$ & $6.18 \mathrm{a}$ & $0.559 \mathrm{a}$ & $0.026 \mathrm{a}$ & $0.186 \mathrm{a}$ \\
& Symptomatic & $0.787 \mathrm{~b}$ & $3.50 \mathrm{~b}$ & $0.325 \mathrm{~b}$ & $0.013 \mathrm{~b}$ & $0.093 \mathrm{~b}$ \\
\hline & Healthy & $0.714 \mathrm{a}$ & $5.05 \mathrm{~b}$ & $0.441 \mathrm{a}$ & $0.019 \mathrm{a}$ & $0.137 \mathrm{a}$ \\
& \multirow{2}{*}{ May } & Asymptomatic & $0.791 \mathrm{a}$ & $6.81 \mathrm{a}$ & $0.476 \mathrm{a}$ & $0.020 \mathrm{a}$ & $0.149 \mathrm{a}$ \\
& Symptomatic & $0.834 \mathrm{a}$ & $5.81 \mathrm{a}$ & $0.446 \mathrm{a}$ & $0.017 \mathrm{a}$ & $0.130 \mathrm{a}$ \\
\hline & $P$ & 0.005 & 0.013 & 0.022 & $<0.001$ & $<0.001$ \\
\hline
\end{tabular}

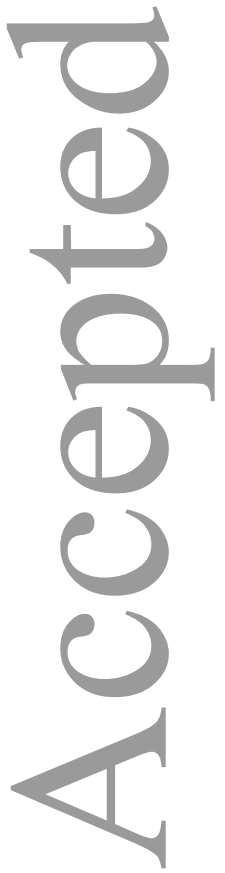


Figure 1. Relationships between peel color index and total acidity of control (CTR), asymptomatic (AS) and symptomatic (showing HLB symptoms, INF) 'Valencia' orange
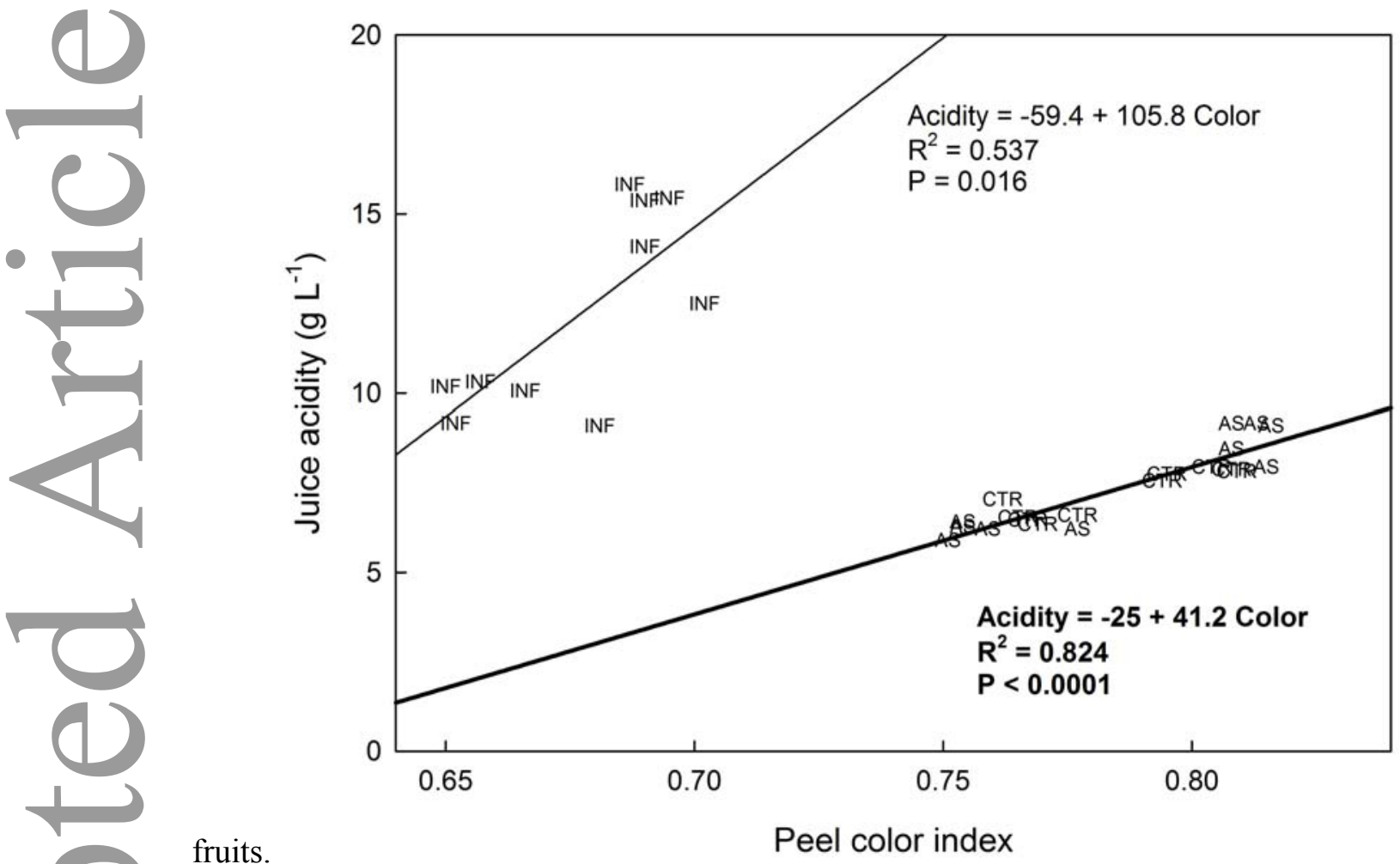

fruits.

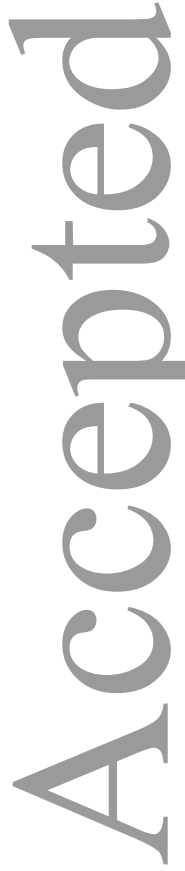

This article is protected by copyright. All rights reserved 
Figure 2. Relationship between peel color index and soluble solids of control (CTR), asymptomatic (AS) and symptomatic (showing HLB symptoms, INF) 'Valencia' orange
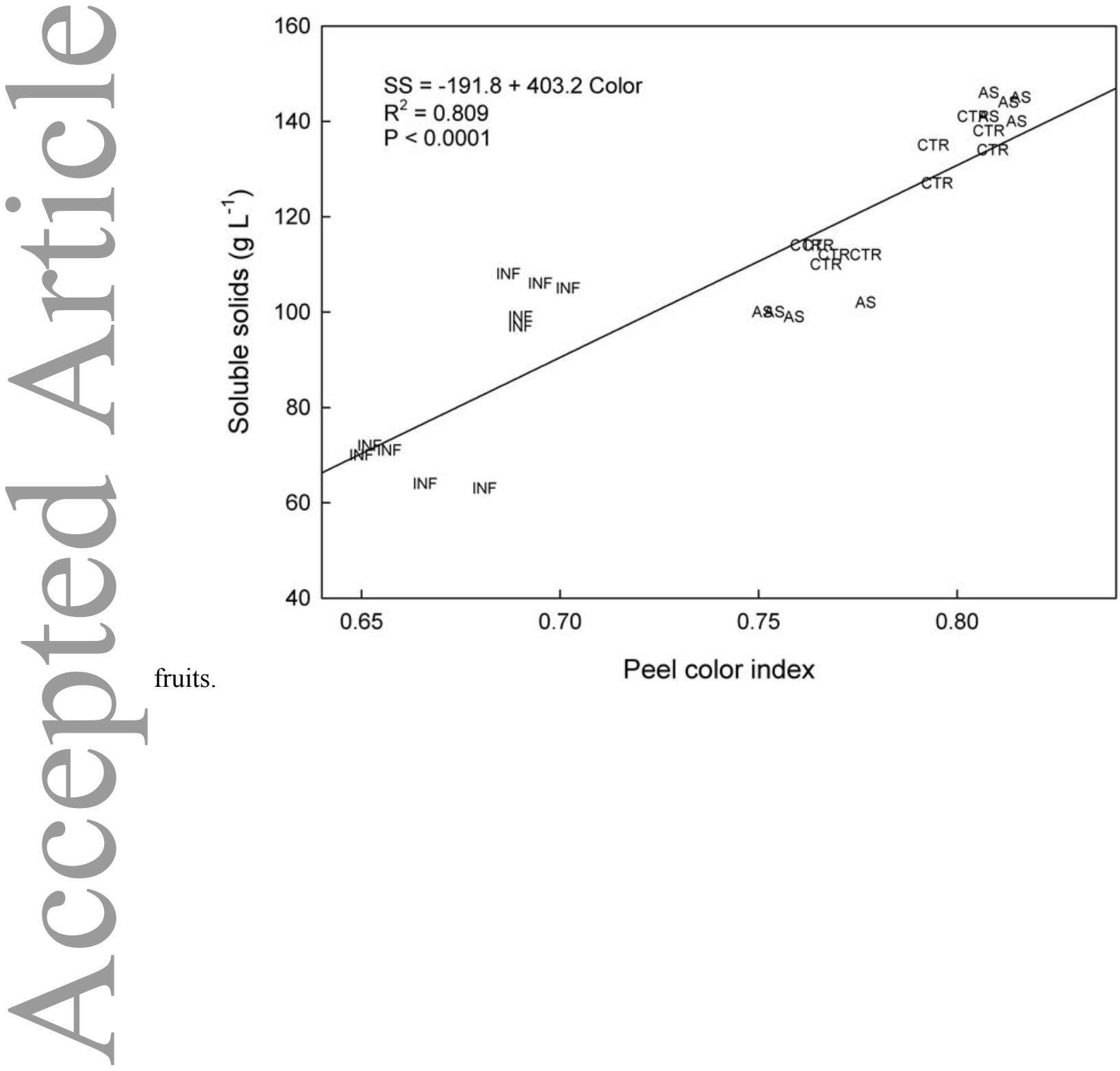

This article is protected by copyright. All rights reserved 